\title{
Pleural endometriosis associated with catamenial hemothorax: a case report
}

\begin{abstract}
Pleural endometriosis is a rare condition that leads to anxiety and suffering on affected patients. We suspect of pleural endometriosis when pulmonary symptoms are associated with the menstrual cycle. We report a case of a 40year-old nulligravid patient who presented dispnea and thoracic pain during menstruation. The diagnosis was confirmed based on biopsy performed during exploratory thoractomy procedure.
\end{abstract}

Keywords: gynecology, endometriosis, hemothorax
Volume 5 Issue 6 - 2017

\author{
Edinari $\mathrm{N}$ de $\mathrm{S}$ Lopes, Lia CV da C Damasio, \\ Edmund C Baracat, Allana Karine L Riberio \\ Sra, Janine L de M LJ Lopes Sra, Dennyse de \\ MG Albuquerque
}

Department of Gynecology, Universidade Federal do Piauí, Brazil.

Correspondence: Edinari Lopes, Universidade Federal do PiauÃ, Rua Pe Cirilo Chaves, Bairro Dos Noivos, Teresina-Piauã, I5 I 5, Brasil, Tel +55(86)994653030,

Email edinarinunes@hotmail.com

Received: August 0I, 2017 | Published: August 2I, 2017

\section{Introduction}

Endometriosis is a benign condition in which endometrial stroma and glands are found outside the uterus. ${ }^{1}$ The mean age at diagnosis varies from 25 to 35 years old ${ }^{2,3}$ and the most common affected areas are the uterosacral ligaments, the rectouterine and vesicouterine excavations, the uterine tubes, the sigmoid colon and the round ligaments. ${ }^{4}$ Pleural endometriosis is a rare form of endometriosis and its incidence among general population is still unknown. It was observed in less than $1 \%$ of the women who have had surgery due to a suspicion of pelvic endometriosis and in $3 \%$ to $6 \%$ of women who have presented spontaneous pneumothorax. We report a case of a patient who presented catamenial hemothorax related to pleural endometriosis. ${ }^{5,6}$

\section{Case}

A 40year-old nulligravid female patient presented to the emergency room with a 2 month history of progressive dispnea associated to right thoracic pain. The patient was submitted to a relieve thoracocentesis with drainage of 1.5liter of hematic liquid and then she was transferred to our service. Chest radiography revealed unlimited opacities in lower lobe of the right lung associated to ipsilateral costophrenic angle obliteration. Thus, the patient was submitted to exploratory thoracotomy which showed bloody pleural effusion. Pleural biopsy was compatible with the dignosis of pleural endometriosis. On physical exam patient presented pulmonary auscultation with diminished vesicular murmur on lower third of right hemithorax. On gynecologic exam we observed endometrial implant on the posterior comissure of the vagina as well as thickness of uterosacral ligaments. Transvaginal ultrasound revealed a lesion on the right ovary measuring $4 \mathrm{~cm}$ in length and CA 125 level was 113.6. The patient is currently under treatment with desogestrel and the pulmonary simptoms have been stable.

\section{Discussion}

Extrapelvic endometriosis is a associated to a variety of symptoms which depend on the affected organs. ${ }^{7}$ Thus, physical findings are related to the location and extension of the disease. ${ }^{8}$ Diagnosis is more accurate during menstruation. ${ }^{9}$ In our report we suspected of pleural endometriosis due to the cyclic pleural effusion and to the bloody fluid that was drained during the thoracocentesis procedure. Thoracic endometriosis can be defined as presence of endometrial stroma and/or glands in the lung parenchyma and/or pleura, airways and diaphragm. Some procedures, such as thoracic tube aspiration, thoracotomy and bronchoscopy, can be used to identify endometrial implants. ${ }^{10}$

Symptoms tend to be cyclic and to be worsened during menstruation. Clinical manifestations varies according to the affected areas. Thus, when endometrial implants occur in the pleura the patient may present catamenial pneumothorax or hemothorax. When the lung parenchyma is affected the patient may present catamenial hemoptysis or assymptomatic lung nodules. ${ }^{11,12}$ As we observed in our patient, pleural implants are more frequent on the right side, possibly due to cogenital defect of the right diaphragmatic hemi-cupula and the continuous fluid flow from pelvis to abdominal right upper quadrant. They can present as a unique or as multiple implants and its length varies from $1 \mathrm{~mm}$ to some centimeters. Usually pleural implants are red colored. However they can also present in diferent shades of grey, including white. During bronchoscopy these implants can be seen in the tracheaobrochial tree. ${ }^{13}$

Although some risk factors for pelvic endometriosis have been described, such as short menstual cycles, nulliparity, early menarche and late menopause, it is still unknown if they increase the risk of thoracic impairment. ${ }^{14}$ The most common complementary test is the chest radiography which might reveal frequent changes such as pneumothorax, hemothorax with or without mediastinal deviation and parenchymatous nodules. ${ }^{10} \mathrm{CT}$ must be performed in symptomatic patients with normal chest radiography. $\mathrm{Ca} 125$ level can also be 
elevated in those patients but this measure has low sensitivy and specificity. ${ }^{15,16}$ Initial treatment for pleural endometriosis associated with pleural effusion consists in urgent thoracic drainage. Significative hemorrhage is rare in patients with endometriosis, however, if more than $20 \mathrm{~mL} / \mathrm{kg}$ is drained, urgent thoracotomy and segmentectomy of the endometrial implants must be performed. ${ }^{17}$ Following these procedures patient must receive hormonal therapy in order to suppres ovarian steroidogenesis, which include oral contraceptives, progestagen, danazol and GnRH agonist drugs. It is recommended that the treatment lasts at least 6 months. ${ }^{10}$ Briefly we reported a rare case of pleural endometriosis associated with catamenial hemothorax of which description and literature review allow other health professionals to be alert regarding this condition, its proper dignosis and treatment.

\section{Acknowledgements}

None.

\section{Conflict of Interests}

The authors declare that they have no conflict of interests.

\section{References}

1. Fritz MA. Leon Speroff. Endocrinologia, ginecologia e infertilidade. 2015;29:1259.

2. Kuohung W, Jones GL, Vitonis AF, et al. Characteristics of patients with endometriosis in the United States and the United Kingdom. Fertil Steril. 2002;78(4):767-772.

3. Hediger ML, Hartnett HJ, Louis GM. Association of endometriosis with body size and figure. Fertil Steril. 2005;84(5):1366-1374.

4. Jubanyik KJ, Comite F. Extrapelvic endometriosis. Obstet Gynecol Clin North Am. 1997;24(2):411-440.

5. Guo SW, Wang Y. The prevalence of endometriosis in women with chronic pelvic pain. Gynecol Obstet Invest. 2006;62(3):121-130.
6. Viganò P, Parazzini F, Somigliana E, et al. Endometriosis: epidemiology and aetiological factors. Best Pract Res Clin Obstet Gynaecol. 2004;18(2):177-200.

7. Fritz MA. Leon speroff: endocrinologia. Ginecologia e infertilidade. $2015 ; 29: 1272$

8. Vercellini P, Trespidi L, De Giorgi O, et al. Endometriosis and pelvic pain: relation to disease stage and localization. Fertil Steril. 1996;65(2):299304.

9. Koninckx PR, Meuleman C, Oosterlynck D, et al. Diagnosis of deep endometriosis by clinical examination during menstruation and plasma CA-125 concentration. Fertil Steril. 1996;65(2):280-287.

10. Alifano M, Jablonski C, Kadiri H, et al. Catamenial and noncatamenial, endometriosis-related or nonendometriosis-related pneumothorax referred for surgery. Am J Respir Crit Care Med. 2007;176(10):1048-1053.

11. Barbosa BC, Marchiori E, Zanetti GMR, et al. Peneumotorax catamenial. Radiol Brasil. 2015;48(2):128-129.

12. Costa F, Matos F. Endometriose torácica. Rev Port Pneumol. 2008;14:427435.

13. Channabasavaiah AD, Joseph JV. Thoracic endometriosis: revisiting the association between clinical presentation and thoracic pathology based on thoracoscopic findings in 110 patients. Medicine (Baltimore). 2010;89(3):183-188.

14. Jose JV. Thoracic endometriosis: Pathogenesis, epidemiology, and pathology. Up To Date; 2017.

15. Rousset $\mathrm{P}$, Rousset-Jablonski $\mathrm{C}$, Alifano $\mathrm{M}$, et al. Thoracic endometriosis syndrome: CT and MRI features. Clin Radiol. 2014;69(3):323-330.

16. Tsunezuka Y, Sato H, Kodama T, et al. Expression of CA125 in thoracic endometriosis in a patient with catamenial pneumothorax. Respiration. 1999;65(5):470-472.

17. Sevinç S, Unsal S, Oztürk T, et al. Thoracic endometriosis syndrome with bloody pleural effusion in a 28 year old woman. J Pak Med Assoc. 2013;63(1):114-116 